le portiQue Le Portique

le portiQue Revue de philosophie et de sciences humaines

$10 \mid 2002$

Les paradis artificiels

\title{
Index des collaborateurs
}

\section{(2) OpenEdition}

1 Journals

\section{Édition électronique}

URL : http://journals.openedition.org/leportique/166

DOI : $10.4000 /$ leportique. 166

ISSN : $1777-5280$

Éditeur

Association "Les Amis du Portique"

Édition imprimée

Date de publication : 1 septembre 2002

ISSN : 1283-8594

Référence électronique

«Index des collaborateurs », Le Portique [En ligne], 10 | 2002, mis en ligne le 08 mars 2005, consulté le 11 avril 2021. URL : http://journals.openedition.org/leportique/166 ; DOI : https://doi.org/10.4000/

leportique. 166

Ce document a été généré automatiquement le 11 avril 2021.

Tous droits réservés 


\section{Index des collaborateurs}

1 Nicolas Antenat, professeur de philosophie, travaille, dans une approche phénoménologique, sur les rapports entre éthique et esthétique et s'intéresse à la problématique de l'interruption.

2 Jacqueline Carroy, Directrice d'Études à l'École des Hautes Études en Sciences Sociales (E.H.E.S.S.), travaille sur l'histoire de la psychologie et de la psychopathologie au XIX siècle. Outre de nombreux articles, elle a publié Hypnose, suggestion et psychologie. L'invention de sujets (Paris, PUF, 1991), et Les Personnalités doubles et multiples entre science et fiction (Paris, PUF, 1993).

3 Pierre-Paul Costantini est psychologue, membre de l'Association de la Cause freudienne (ACF), expert près du Tribunal de Grande Instance de Metz. Il travaille au Service Médico-Psychologique Régional de La Maison d'Arrêt de Metz. Ses recherches sont liées à sa pratique et ont pour objet le passage à l'acte et la perversion. Dernière publication : «Ceci n'est pas un pied », in Temps psychiques et temps judiciaires, colloque de Rennes, à paraître en 2003.

4 Claude Escande est Docteur en Psychologie et en Psychopathologie et Professeur associé à l'Université Louis Pasteur de Strasbourg.

Benoît Goetz, philosophe, professeur agrégé de philosophie, enseigne à l'Université de Metz. Il est l'auteur de nombreux travaux sur l'esthétique et l'architecture.

6 Raphaël Herr est psychologue clinicien. Il exerce au centre hospitalier de Jury-lèsMetz.

7 Pascale Jamoulle est anthropologue au Laboratoire d'Anthropologie Prospective (LAAP) de l'université de Louvain-la-Neuve et au Centre de Santé Mentale du Centre Public d'Aide Sociale de Charleroi (Belgique).

8 Catherine Jordy est docteur en histoire de l'art. Sa thèse porte sur La Peinture romantique en Alsace (1780-1880). Elle a publié en 2002 L'Alsace vue par les peintres aux éditions Serge Domini.

9 Michèle Kuntz a une double formation de psychologue et d'historienne. Son doctorat d'histoire sur l'urbanisme à Metz au XIX siècle a été l'objet d'une publication. Les dix dernières années d'une carrière de psychologue ont été consacrées aux soins aux 
toxicomanes, qui ont donné lieu à un ouvrage : Les Toxicomanes. Du goût de la drogue au goût de la contrainte, Paris, L'Harmattan, 1998.

Stéfan Leclercq est le responsable du Fonds documentaire Gilles-Deleuze, bibliothèque du Sauchoir à Paris. Il est le directeur des éditions Sils Maria et directeur de publication de la revue de philosophie Concepts. Dernière publication: L'Expérience du mouvement dans la peinture de Francis Bacon, L'Harmattan, 2002. Univocité, répétition et devenir (avec Arnaud Villani) in Vocabulaire de Gilles Deleuze, revue Noesis, Université de Nice \& CNRS, à paraître, 2002.

11 Dominique Marinelli, psychologue et psychanalyste à Metz, est chargée d'enseignement aux Universités de Metz et de Strasbourg. Travaux de recherche et articles sur la féminité, la littérature et la psychanalyse, le suicide des adolescents, etc.

Jean-Paul Méloni est éducateur spécialisé, Responsable du Secteur du Val de Sarre qui regroupe les équipes de Prévention de Sarreguemines et de Sarrebourg (C.M.S.E.A.). Il termine une thèse en ethnologie sur le phénomène techno et les liens entre les drogues et la fête. Dernière publication : «Rave-party : rituel festif de la jeunesse », revue La Vie et la Santé 19, 2002.

Éric Navet est Professeur, Directeur de l'Institut d'Ethnologie à l'Université Marc Bloch de Strasbourg et du Centre de Recherches Interdisciplinaires en Anthropologie (CRIA). Auteur d'une soixantaine d'articles scientifiques sur les Indiens subarctiques (algonquins) du Canada et les Indiens de la Forêt tropicale (Guyane française). Auteur de: Les Indiens d'Amérique du Nord. Problèmes politiques et sociaux (Dossiers d'actualité mondiale), $\mathrm{n}^{\circ} 448$, octobre 1982, Paris, La Documentation Française ; Ike min anam. «Il était une fois... la "dernière frontière" pour les peuples indiens de Guyane ", Épinal, Éd. Nitassinan, 1990 ; "Car les fleurs sont comme de petits enfants ». Essai sur le mode d'être et de penser des Indiens Ojibwé (à paraître aux Presses de l'Université de Paris 7, 2003). Coauteur de Contes amérindiens de Guyane, Paris, Conseil International de la langue française (CILF), 1987, etc.

Jean-François Poirier est écrivain et traducteur d'allemand, spécialiste de Walter Benjamin, producteur avec Jean-Loup Thébaud de l'émission de philosophie « Le Diwan des deux rives » sur Radio-Méditerranée 88.6.

Michel Rosenzweig, de formation philosophique et psychanalytique, est chargé de cours à l'Université de Paris VIII et responsable de la rédaction belge de la Revue internationale de toxicomanies psychotropes. Sa formation de psychanalyste ainsi que son orientation historique dans la philosophie lui ont permis d'acquérir un regard multiple, critique et questionnant sur les drogues. Il est l'auteur, notamment, d'un ouvrage intitulé : Les Drogues dans l'histoire. Entre remède et poison, archéologie d'un savoir oublié, De Boeck Université, coll. « Comprendre », Paris/Bruxelles, 1998.

Jean-Yves Trépos est professeur de sociologie à l'Université de Metz. Ses travaux, au sein du laboratoire ERASE, sont consacrés aux rapports entre les experts et les nonexperts sur divers terrains: il observe à la fois la distribution des compétences (Sociologie de la compétence professionnelle, Presses Universitaires de Nancy, 1992) et l'effort qu'accomplissent différents spécialistes pour en revendiquer le monopole ( $\mathrm{L} a$ Sociologie de l'expertise, PUF, 1996). Attentif à la fabrication des sciences sociales, il a consacré ses plus récentes recherches à l'écriture de la sociologie (ouvrage à paraître chez Nathan). 